Send your research letters to the editor British Dental Journal, 64 Wimpole Street, London W1G8YS E-mail bdj@bda.org Priority will be given to letters less than 500 words long. Authors must sign the letter, which may be edited for reasons of space

\section{Conflicting viewpoints}

Sir, your recent editorial Prove it (BDJ 199; 1 : 1) was well thought out and I believe has great relevance to the subject of the diagnosis and treatment of TMD.

The occlusion, jaw and jaw joint relationships, together with the muscles, ligaments, bones and their blood and nerve supply, constitute the stomatognathic system. Controversy regarding the dynamic interrelationships of this highly complex system has raged for generations of dentists since before the time of Costen. Perhaps no other author or researcher has been so widely quoted or so deeply misunderstood and the differences of opinion are as marked today as they were when Costen first published his findings in $1934 .^{1}$

The main controversy revolves around the diagnosis and treatment of the system when it goes wrong. The two main camps divide unevenly between the "stress and psychology' and the 'abnormal structure and function' schools of thinking. The structure and function of the stomatognathic system can be affected in many ways without the patient becoming symptomatic. Patients can become stressed, leading to bruxing, which in turn can cause structural problems. Individual adaptive capacity, stress levels and sensitivity vary considerably so one patient may be symptomatic while the other is not.

For many TMD patients, conservative treatment - such as rest, relaxation, analgesics or part-time occlusal splint use - can be effective in reducing symptoms. In chronic cases where conservative methods have failed, functional jaw orthopaedics (which aims to correct the underlying structural malrelationships) has a definite place and should be recommended prior to considering surgery. Many of these patients have internal derangements, which Isberg $^{2}$ showed could cause neural entrapment within the joint. Her research vindicated Costen's earlier work and provided an anatomical explanation for many TMD symptoms.

Deeply entrenched views have, unfortunately, led to unnecessary litigation and treatment initiative has been stifled by fear of prosecution. The increase in cases in both the GDC and civil courts could be avoided with a more comprehensive and up-to-date appreciation of the vast amount of literature. In the absence of the perfect study, the practitioner must base his diagnosis and treatment on clinical judgement - a combination of his knowledge and experience. No one denies the importance of rigorous scientific testing but clinical judgement should always be regarded as the final arbiter.

Despite the risks of possible litigation, the practitioner has a duty to carry out treatment in the patient's best interests. To refuse treatment on the grounds that there is no absolute certainty it will work could condemn the patient to unnecessary and prolonged suffering. It would be morally indefensible and cowardly to withhold treatment you consider might be effective on the grounds that the evidence base has not been firmly established.

Unfortunately, when viewpoints become polarised, it is difficult to find common ground. Often, research papers are scrutinised for flaws that diminish the profound implications of much of the clinical findings. This 'line of best fit' mentality can lead to loss of invaluable results. Truth can become the victim if studies are subjected to the exacting requirements of randomised control trials. In general, clinicians are results-orientated. Much of the research done in clinical practice is criticised for lack of controls, while, as stated in the editorial, evidence-based knowledge suggests that more research is required before we can be certain. This does not help the long-suffering TMD patient or the practitioner who faces

TMJ/orthodontic litigation. Since all practitioners encounter some failures, greater understanding and tolerance are

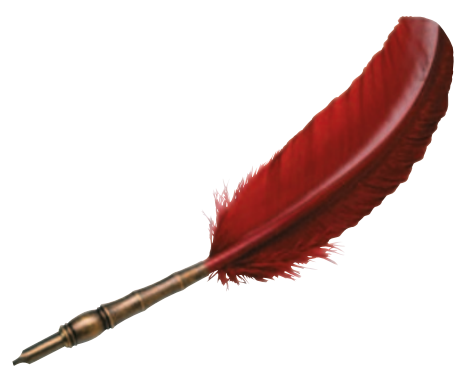

necessary to allow respect for different viewpoints.

R. Dean

By email

doi: 10.1038/sj.bdj.4812861

1. Costen J B. A syndrome of ear and sinus symptoms dependent upon disturbed function of the temporomandibular joint. Annals Otol Rhin Laryngol 1934; 43: 1-15.

2. Isberg. Temporomandibular joint dysfunction. p 139. UK: Isis Med Media, 2001

\section{Insufficient incentives}

Sir, it was refreshing to read Aubrey Sheiham's editorial in the British Dental Journal (2005; 199: 187) - Delivering dental care: changing needs and future requirements.

I quote: 'The dramatic improvements in dental health are a good test bed to evaluate the openness to change in dentistry.'

In the future it is likely that most people will require little dental care and most interventions will be simple; this is highlighted in the editorial.

As a practising general dental practitioner, I certainly agree with Professor Sheiham that there are insufficient incentives at present to stimulate activity in the direction of health improvement. Dentists should be rewarded on 'reducing treatment need' and 'activities that are less interventionist'. This would inevitably catalyse a clinician to care for greater numbers of patients, particularly if career pathways were developed along the lines outlined in the editorial.

The challenge for Government and PCTs/LHBs is to recognise models of care that demonstrate reduced treatment need through being less interventionist, that is person-centred care as opposed to treatment-centred care. Local commissioning could facilitate this but only if PCTs/LHBs are astute enough to recognise, and courageous enough to support, practices which generate outcomes that are different from the norm but in tune with health policy. W. Richards

By email doi: 10.1038/sj.bdj.4812862 